\title{
If Designers are Problem Solvers: What is a "Real" Problem, A Problem for Whom?
}

\author{
Philip G. C. Whiting, Griffith University, Queensland, Australia
}

\begin{abstract}
Meikle describes American industrial designers in the 1940's as nothing more than a service to industry and responsible for the development of consumerism, rather than solving real problems? What is a real problem as opposed to a perceived problem or even a wicked problem? Problems always exist in one form or another, so should designers begin to view the world in a more scientific way and look for real problems within situations that require resolution, in the way that Heidegger asks the question: What actually calls for thinking?; real food for thought as opposed to reactive design thinking. It could be argued that designers such as Dyson already do this to some extent, but should not all designers become much more proactive in terms of path-finding, leading and design management? Designers today only provide assistance when they should provide overall direction or redirection for tomorrow. Redirecting and addressing the impact of socio-economic problems we are now facing, as well as climatic change or natural disaster especially where there is potential for re-occurrence and the real problem may be floods, storms, volcanos, erosion, rising tides, extreme heat or cold. In a sense we tend to treat our environments as a constant war with nature, yet earlier thinking; due in part to limitations of machine and lack of technology in the past, was to adapt to our environment. Today we solve many problems by simply trying to dominate nature as we possess the power and technology to do this, without fully appreciating the long term implications of our designs. To begin to solve this real problem we have to move the designer from a reactive service industry to proactive design thinking, path-finding and profession of leaders.
\end{abstract}

Keywords: Design Management, Design Thinking, Sustainability, Consumers

\section{Introduction}

$\mathrm{A}$

PROBLEM IS perceived in different ways depending upon the perspective of those viewing the problem. In certain circumstances it is not even seen as a problem as such. Does this suggest that these differing perspectives (or viewpoints) are seen as various problems around the real problem? Does this in turn suggest that the problem central to all those various and differing perspectives is in fact the real problem? If this is the case then how does one arrive at this central point? Do the various views have value or are they symptoms that direct us towards the cause? What does potentially become clear here is a need to make an accurate diagnosis of the central problem, otherwise one runs the risk of treating the symptoms and not the cause, in this case the real problem. From a commercial or retail perspective there are four main players, but only two key players who determine the problem to be solved. The first being the client who sees an opportunity to profit from the needs of the user who in turn is the second key player. The designer is perceived as a main player, but has limited influence and is reactive in creating a commercially viable outcome based upon the needs of the client and user. Sustainability in its various forms is now the fourth main player, but is influenced by the client and/or the user rather

Design Principles and Practices: An International Journal

Volume 5, Number 3, 2011, http://www.Design-Journal.com, ISSN 1833-1874

(C) Common Ground, Philip G. C. Whiting, All Rights Reserved, Permissions:

cg-support@commongroundpublishing.com 
than by the designer. Figure 1 tries to demonstrate this in simplistic terms, where these four typical commercial key players are highlighted, the view and needs of the client, the view and needs of the end-user, the view of the designer and the needs of limited sustainability.

The real problem is thus central to all these view-points and needs to be considered, and at first sight this suggests a well rounded approach. The reality is very different as many other views are either not considered at all or are heavily influenced by the needs and views of the client. The end-user need is more likely a commercially created need as opposed to a real need; critical decisions on sustainability are at best a token approach where the demands of the client directly influence the view of the designer. Sustainability is introduced here as an important and 'critical' viewpoint with a more wide and far-reaching perspective than is currently understood or appreciated by many. It is not however necessarily the real problem in itself.

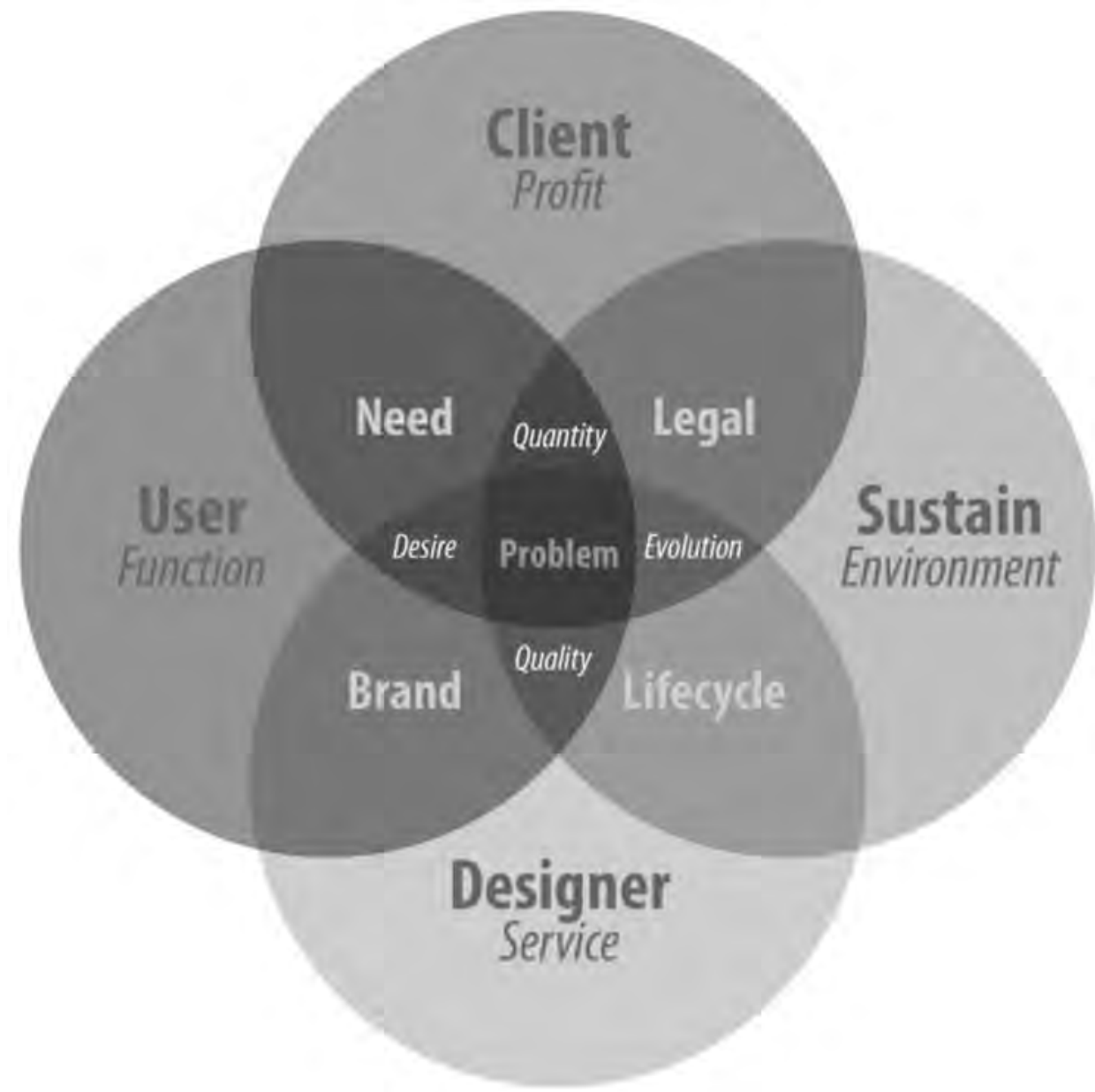

Figure 1 


\section{Critical Decisions}

I originally introduced the premise of a limited number of 'critical' decisions during the process of developing a design concept through to its final 2D/3D interpretation. (Whiting 2009). Within the design process exist almost any number of decisions required to move a concept/design solution forward, however there is only a limited number of what I call 'critical' decisions that impact significantly upon the final outcome. This premise is of course based upon the traditional model of how a designer presently works. The designer, as a service provider, is presented with a perceived problem by a third party that has been pre-defined from their particular field or limited viewpoint. The more critical designer will endeavour to research further in a genuine effort to better understand the perceived problem and provide a return brief which may or may not shift the perception closer to identification of the central problem facing the third party. The accurate identification of this central key issue or real problem is in one sense the most critical decision to make at the outset and yet is already defined and decided by others; leaving the designer to do no more than provide more depth to this one-sided view of the problem. (Heidegger 1968). The critical flaw in this relationship between designer and client is seeing the 'problems' presented to designers as problems. In fact the designer is not presented with a problem to solve, but is presented with a specific need by the third party. The design solution eventually provided is designed to effectively meet that need. Thus, the designer is not really solving a problem, but servicing a specific perceived need (or consumer desire) as directed by others. Is it possible to define a real problem from a design viewpoint as opposed to that which is only a perceived problem and who should have the responsibility to do this objectively?

\section{Perspectives: Perceived Problems, Needs \& Desires or Real Problems?}

Like beauty it is conceivable that a problem is only seen within the eye of the beholder. For the designer to truly be a problem solver in a scientific sense, it is critical for the designer to identify what is a real problem in the first place. Otherwise they run the risk of continuing to simply react to or service the needs and desires of others. Whilst it could be argued that the latter can equally be seen as scientific research, it is however tainted or limited at the outset. At this point there is a need to define the use and interpretation of scientific as the terminology used to in turn define a real problem solver. I introduce design as the preliminary centre point between Art and Science, where art is seen as ephemeral and science seen as serious and authoritative. Tony Fry in his book (Remakings 1994) draws our attention to a contrast between a scientistic viewpoint and the claimed ability of science and technology to rectify the problems that science created. However rightly or wrongly scientific research has a basic level of understanding and respect which I use here to differentiate between that of perceived problem solving or servicing the limited needs and desires of others. The onesided view of the problem if you like, as opposed to a more ontological understanding of problem solving is seen as having real meaning and positive impact for both the designer and the eventual recipient(s) in terms of a comprehensive range of perspectives including sustainability and ecodesign.

I introduce here a starting point where the 'perceived' problem is identified as that which appears immediately obvious. Not a knee-jerk reaction as such, rather something that is seen as a need or the potential for a need, which in itself is a somewhat ridiculous statement. A 
need is either there or not, there is no 'potential' for need; it is more likely to actually be the potential for a desire which in itself is artificially created through spin doctoring, advertising and marketing. In this case the view of the need is constricted, constrained and limited by the narrow viewpoint of those who have identified a need for themselves. It does not by definition necessarily meet the real needs of others. A commercial operation or venture will inevitably have a real financial need; without profit it cannot prosper and develop. Thus there is a need to profit, but the problem becomes that of how to go about creating profit and this is a critical decision from any viewpoint. Should the focus remain as that of simply creating profit for its own sake? If so then we begin to identify the flaw that creates the negative impact of our consumer economy model, whereby it does not matter what is produced as long as it turns a profit in the short-term. According to Meikle (1979) the consumer is both the accomplice and the victim, manipulated yet happy to be so as the end product supposedly justifies the means. The argument was that strong demand and mass production led to reduced costs to benefit all, but no account is taken regarding the long term ecological footprint, the damage and the real cost we are now faced with some eighty years on since those observations were made in the book Twentieth Century Limited. Today's sophisticated communication, marketing, advertising techniques and strategies allow us to create shortterm demand (through desire), a false (or artificial) need for something based upon a perceived problem that is incorrectly identified as the real problem in an effort to drive our economic model.

Is the economic model of a stock exchange itself based upon an inaccurately perceived problem or need to generate profits, thus inadvertently creating profit-driven companies and in doing so ignoring the real problem of how best to generate those profits? I introduce two preliminary commercial examples of reinvented brands: Triumph Motorcycles in the UK which is still privately owned, and Harley Davidson Motorcycles, a company listed on the NYSE to demonstrate the point.

For Triumph Motorcycles the need to make and continually develop a quality product is central to their real problem and one they successfully address through continual development. In a rare interview in 2005, John Bloor who owns Triumph Motorcycles was quoted as saying, if I am proud of anything it's that we've kept making little progressions each year. There are no high moments or low moments, just continuous improvements. This continuous improvement relates to every single aspect of their product range as well as an in-depth understanding of their long-term future customer and not unlike Apple, Triumph Motorcycles not only understands their past and present customers, but are directing their existing and future customers using design as the key ingredient. Tony Fry (A New Design Philosophy 1999) highlights how Design is one of the most powerful ways to understand how a world is pre - figured, made and acts. Through design research Triumph Motorcycles are able to understand both the negative and positive impact of what they do prior to market release. Triumph Motorcycles are not only able to respond to automobile environmental legislation, but are also beginning to lead and direct in this area. The real problem for Triumph Motorcycles is to determine how motorcycles (however designed) can be a viable form of transport in the future. This has translated into the development of both a strong brand and increasing profits, which was clearly demonstrated during the worldwide financial meltdown in 2009/10 where Triumph Motorcycles continued to prosper and develop even though profit for its own sake is not the main focus. 
In contrast we have the near financial collapse of many listed companies including Harley Davidson Motorcycles. On the face of it and to the outside observer it would appear to be in a similar category to Triumph Motorcycles in terms of its product and the re-born brand. Harley Davidson has a focus purely on their brand rather than the quality of their product(s), products still based upon old technology and retro styling. Here design development is often restricted to the superficial cosmetic in every sense to maintain their brand image in a shortterm effort to maximise profits to shareholders. During the boom period at the start of the $21^{\text {st }}$ century they went from strength to strength, but when the financial climate changed Harley Davidson was viewed as nothing more than an unnecessary luxury item for most consumers who now walked away in droves. Here the object becomes more than just its actual function, which only has limited value in real terms, the value we place on a object relates to its meaning within our life and/or the life of others. (Jean Baudrillard 1981). There is no argument that other factors beyond design are at play here, however even the most basic research into business does seem to suggest that it is not simply using design that makes a difference. It is 'how design is used' and that brings us back to the critical identification or definition of the real problem as opposed to the partial perspective of a perceived problem, symptom or artificial need.

\section{Wicked Problem?}

Assuming we have now begun to identify the central or real problem in relation to a perceived problem, what about wicked problems? Jeanne Liedtka (2004), refers to design theorist Horst Rittel who first called attention to what he described as the wicked nature of design problems. "Such problems have a unique set of properties", he argued, "the most important of which is that they have no definitive formulation or solution. The definition of the 'problem' itself is open to multiple interpretations, dependant upon the weltanschauung, or worldview, of the observer, and potential solutions are many, with none of them able to be proven to be correct." This description by Rittel matches much of what is already written here, with the one exception where I posit 'potential solutions' as scientific research exercises and used for hypothesis-gathering models for direction towards the real problem. Tony Fry (Remakings 1994), makes the statement, "Moreover, 'solutions' have to be viewed as even more ungrounded and fabricated than 'need'. It follows that a solution, to be a solution, is measured against an evaluation of a need that is established as actual need". Liedtka goes on to suggest that the scientific method, with its emphasis on cycles of hypothesis-generating and testing and the acquisition of new information to continually open up new possibilities, remains central to design thinking. If this is true, we return to multiple perspectives, views or symptoms that may provide direction to a central point or key issue as to what is a real problem and how to identify it.

\section{What is a Real Problem, how can we Identify it?}

It is not necessarily the role of the designer as the only one capable of identifying a real problem. That role is obviously available to anyone, but for those unable to do this, it is critical the designer is able to provide redirection through research and design management of a project. It is not critical who actually defines a real problem as long as it is determined and identified as the 'real problem' equally identifying that it does in fact address a real 
need. Tony Fry (Remakings 1994) also makes the point that; 'Need', however cannot be viably viewed from one perspective as a singular object. It is itself non-discrete; it bleeds into many other categories - demand, necessity, desire, want, poverty and so on. Need 'real' or otherwise is not only a moving target, but its interpretation is continually altered depending upon the perspective of the viewer or their place in society. He goes on to suggest that, even from this cursory introduction it should be apparent that to fully interrogate 'need' would be a substantial task. Thus, if 'need' is ever-changing can it really be interrogated in a useful way, is it better to try to devise a formula or model that allows us to understand how the principle of need works in any given situation at any given time? Is design using a scientific experimental approach in a much more creative and effective way?

Having already briefly discussed the consumer based needs for sustainable development identified by the typical commercial venture (Triumph Motorcycles) whereby 'quality' rather than quantity is one of the determining factors, Tony Fry (Remakings 1994) arrives at a similar position, but from a slightly different viewpoint. Ecodesign, as a design practice, travels in two directions that converge: it moves towards the creation of an economy that can produce while reducing ecological damage; while at the same time, it seeks to produce wealth while diminishing the volume of resources used. It follows that if ideas like 'ecologically sustainable development', or just sustainability, are to have any agency they need to be reconceptualised in a process that moves from quantity to a quality based economy. By repositioning the designer in the role of scientific researcher and all that title suggests and embodies, this effectively removes the designer from the role of nothing more than a service provider to industry, reacting only to the needs (or desires) of others. The research designer takes on a much more ontological view working with 'real' problems already clearly identified and understood as a 'real' need to be addressed.

Leidtka's (2004) view of science as hypothesis-generating cycles or design models for testing to open up new possibilities fits well with the experimental, trial and error way in which most designers presently arrive at the optimum solution. Referring back to the example of Triumph Motorcycles this could suggest that Jean Baudrillard (1981) has focused upon a somewhat outdated theory of design by stating, one allows it to be understood that, according to a continuous progress, objects would obey an internal aesthetic logic which would ultimately lead them to appear in their "truth", in the harmonious synthesis of their function and their form. Aesthetics in terms of visual appeal (fashion and usability), brand and market segments still play a significant role in consumer decision making and 'truth' as such may be an unrealistic utopian ideal. However, the statement does lend itself to pathfinding and the more scientific experimental approach. Commercial realities are still considered as the designer works within this experimental process; in that sense nothing changes, however the $\mathrm{s} /$ he is no longer constrained by the needs of the client or even the market. $\mathrm{S} / \mathrm{he}$ is now free to meet the real needs of the situation or circumstance that has generated the 'real' problem.

\section{Situations; Real Needs and Real Problems}

Does this present the beginning of a rule for the identification of a real problem, in that it has to meet a real need, and if so does this further suggest is it only generated through the creation of a real situation? 
Heidegger (1968) poses the question "What actually calls for thinking, real food for thought?" Existing or developing situations certainly pose many potential problems as preliminary food for thought at first glance. The socio-economic difficulties, extremes of climate change, natural disasters or simply living within our individual environments, are all situations we need to deal with. Nature is often seen as at the core or root of these situations and the first reaction is to try and dominate or fight nature as we have scientific and engineering capability to do this, but at what cost?

We are reminded by Tony Fry that technology has directed our brute force approach to dealing with our environment and nature, we are structured into a culture that acts to dominate our world and in turn nature, this posits us at war with nature, a war we can and should never win in the long term. We do not understand the implications of our short term domination by technology, but we can certainly experience the eventual impact or results when nature seemingly and effectively fights back with storms, floods, tornados, earthquakes. Nature is a far greater brute force than ourselves, we can mimic the brute force of nature but we cannot control it. It is perhaps worthwhile reiterating that technology carries brute power and has been celebrated as such (A New Design Philosophy Tony Fry 1999) In the past when our capability was often limited, our thinking and approach was to determine ways to work with our environment and nature and the solutions produced were often effective to meet our needs with minimal impact upon nature or the environment. In using 'situations' as food for thought with regards to the real needs of an individual or community the designer can develop a range of models to investigate different outcomes or possible solutions. Beyond this it is incumbent upon the designer to also develop models that investigate the more broad picture, how their design potentially goes on systematically designing and what this spawns directly and indirectly like a growing organic matrix through to its eventual realisation.

\section{Design Designing Systems}

Tony Fry (Design Futuring 2009) reiterates how 'we create a world that others also build upon in turn, each creation creates another either directly or indirectly, and in that sense are we like nature but without a real plan - should we look at evolution to understand and create a cyclical plan, should the strong give way to the weak?' The creation of a matrix-like system or the potential for a system begins with a design solution for a real need and will inevitably create through its very existence. Of course there is another side to this approach and one that has been clearly demonstrated by Apple over the past decade. Tony Fry (A New Design Philosophy 1999) talks about the contest of design, and our proximity to it, now becomes paramount, for design draws the line and determines on which side we fall - this statement could be viewed in two ways where design as defuturing creates two factions: those who understand what needs to be done and those who do not. However if we look at design as it presently stands the factions are those who see it as a service industry and those who see it as pathfinding. Is it pathfinding however, to control the system or perceived control to direct the consumer, as a range of seemingly random products come on-line, yet are deliberately and strategically designed as part of an overall system for Apple? A system that also begins to feed into other areas not directly related to Apple itself. Is this merely a more sophisticated service industry design approach or is it pathfinding or both? Computers already influence or provide a degree of control for much of our waking and sleeping lives and rather than just let it happen it would seem that Apple continues to be proactive in determining how its 
products move us from desire to need and become a necessary part of our existence. Tony Fry (Remakings 1994) discusses need and desire in the following: It will be apparent that 'need' of b eing to being in order to 'need' marks both the transition of culture into political economy and the self to subject. The market displacement and replacement of need as indicated by the stated transition, occurred at the same moment as the elevation of the individuated subject to be named - 'the consumer'. Paradoxically, the very arrival of the desire (as the recent consumer utopianism shown in Eastern Europe indicates), or the freedom, to indulge one's dream - fed needs in the marketplace marks a loss of sovereignty of the self. Which is not to say the market place does meet 'real real' needs - again the problem of distinction returns

Whether this preliminary strategic design system approach proves to be an effective use or abuse of design that goes on designing, only time will tell, however it does demonstrate both the principle and the potential for design to think in terms of three dimensional matrixlike systems when considering any individual design concept to meet a real need rather than designing in isolation and the restricted view of the immediate problem and need. The epistemological research designer carries out a critical study of its validity using a 'real' situation to determine a real need or set of needs to be addressed, through experimentation of situational modelling then identifies possible optimum solutions. These in turn are modelled to identify how, when and where the outcome is used or misused, how it might impact upon other systems, its potential to spawn new design developments or hybrid systems solicited or unsolicited. This is no longer about designing random solutions in terms of clothes, transport, habitat and tools etc., but rather designing them as part of an overall system. This does not remove fashion or individual customisation; it simply alters how we perceive these products. Fashion and usability are also key factors or perspectives in this equation to seek the real problem. However anything that is fashionable has a limited lifespan before it becomes technically unusable. On the other hand usability is about efficiency, performance, reliability, it is the quality of materials, production or manufacture that tends to determine the lifespan of usability. These initially appear as two opposing forces yet could find resolution or salvation within a higher level of customisation or re-thinking how customisation could also function within terms of design and sustainability. As part of a system fashion \& usability as customisation begin to make sense and have relevance to our lives, because they meet an obvious need we understand as end-users, they become not only a necessary need, but a highly desirable or magical need.

Baudrillard (1981) makes reference to this magical as a magical footbridge. Like the concept of need, which is presented as the link between the utility of an object and the demand of a subject, ideology appears as the relation between the projection of the consciousness and the ideality of - vaguely - an idea or a value.

Tony Fry ( $R$ emakings 1994) also explains that whilst desire is important as a tool to be used by design it has no need of investigation for its own sake. The prospect of sitting in judgement on all theories of desire and enacting a ruling is neither contemplated nor regarded as a realistic task. Certainly there is no question of adopting any one of the several available positions on desire and asserting a correct one, for desire is not o ne. Desire (en)folds difference, and therefore is not reducible to one characterisation or set of qualities. Desire is just not to hand to be totalised, reduced to a singular truth or divested of mystery. It follows that all positions on desire inform by what they have thought and make available to think. 
And he goes on to point out: The objective is, of course, not the elimination of desire but its mobilisation and attachment, by design, to objects/commodities that may either be fully consumed, and thereby returned to earth to restore it, or to ones that go on being used as they are remade, repaired or recycled.

\section{Conclusion}

It is clear that design and design thinking are well positioned to define and identify real problems; no matter how 'wicked' the problems surrounding the central issue may first appear. But the anthropocentric, service industry perspective of the designer has to be altered first. Hawken, Lovins \& Lovins (Natural Capitalism 1999) continually draw attention to this by highlighting the following extract. Many architects, engineers, and other designers, however are not being well taught. J. Baldwin, long the technology editor of Whole Earth Review, was told on his first day in design school that design is the art of compromise. Design, he was instructed, means choosing the least unsatisfactory trade-offs between many desirable but incompatible goals. The designer has to be free from existing strictly commercial constraints to consider all possible viewpoints, possibilities and situations. In this way not only are real problems identified, but the impact of solutions can also be mapped and better utilised for future sustainability. The fact that any design goes on designing has been clearly identified by Professor Tony Fry in much of his work and designers need to be able to identify how when and where this is likely to occur, to be able to either direct it and/or allow for its inevitability in a truly sustainable way. The fear for consumers is that by embracing genuine sustainability they will somehow lose the quality of their lifestyle and that as a culture we will begin to move backwards to another time, almost frugal or too heavily constrained and disciplined in how we live. The fear is unfounded if understandable, the role of the designer is to move forward, to continually improve lifestyle, but of course the real problem is that this should not be at the expense of our planet as it is presently.

\section{References}

Baudrillard, Jean (Translated by Charles Levin) (1981) For a Critique of the Political Economy of the Sign Telos Press USA ISBN 0-914386-24-7

Bloor, John (2005) Continuous Improvement Torque, Issue 38, Winter 2005 R.A.T. Hinckley, England Fry, Tony (2009) Design Futuring, Sustainability, Ethics and New Practice University of New South Wales Press Ltd, Sydney Australia ISBN 9781921410840

Fry, Tony (1999) A New Design Philosophy: Introduction to Defuturing University of New South Wales Press Ltd, Sydney Australia

Fry, Tony (1994) Remakings: Ecology, Design, Philosophy. Envirobook, Sydney Australia ISBN 9980858811287

Hawken, Paul; Lovins, Amory B; Lovins L. Hunter (1999) Natural Capitalism Earthscan Ltd. London \& Washington ISBN 978-184407-170-8

Heidegger, Martin (Translated by J. Glenn Gray) (1968) What is called Thinking? Harper \& Row, New York. ISBN 0-06-090528-X1272

Liedtka, Jeanne (2004) Strategy as Design Rotman Management Winter 2004

Meikle, Jeffrey (1979) Twentieth Century Limited: Industrial Design in America 1925-1939 Temple University Press Philadelphia19122 USA

Whiting, Philip (2009) Changing the way designers think! DesignEd Asia Conference, Hong Kong www.sd.polyu.edu.hk/designconference2009 


\section{About the Author}

Philip G. C. Whiting

I have worked for over 30 years in the disciplines of Interior, Product and Visual Communication Design with the focus on total Retail Design, both in the UK and Australia. I strongly believe that the process of design and design thinking can be used to successfully address many of the issues faced by the world today and in the future. My $\mathrm{PhD}$ research is based on this premise and in my position as Convenor, Design Department at Queensland College of Art in Australia we are actively introducing this into the curriculum to redirect the way in which designers work in the future. 